\title{
O surgimento do Ecoville e a dinâmica imobiliária dos edifícios residenciais de alto padrão ${ }^{1}$
}

\author{
El surgimiento del Ecoville y la dinámica de la propiedad \\ inmobiliaria residencial de alto estándar
}

The appearance of the Ecoville and the real estate dynamics of
the high standard residential buildings

\author{
Andresa Lourenço da Silva \\ andresageo@hotmail.com \\ Universidade Estadual de Maringá
}

Márcia Siqueira de Carvalho

marcar@uel.br

Universidade Estadual de Londrina

\begin{abstract}
Resumo: O presente artigo tem como objetivo entender como surgiu o Ecoville e como essa área foi incorporada à dinâmica imobiliária por intermédio da construção de edifícios residenciais de alto padrão na última década (2001-2011). A problemática central deste artigo é entender quais os interesses e as articulações entre os agentes envolvidos que nortearam o crescimento da antiga Conectora 5, hoje denominada Ecoville, e quais fatores determinaram sua verticalização e valorização. A escolha do Ecoville para estudo de caso justifica-se por ser a área de maior interesse do mercado imobiliário de Curitiba, pois tem a maior oferta de imóveis à venda e de terrenos para construção. Nesse sentido, é feito um breve resgate histórico do seu surgimento e sua valorização. Posteriormente, a partir dos dados obtidos através de investigação de campo, foram elaborados tabela e mapas sobre a área de pesquisa.
\end{abstract}

Palavras-chave: Ecoville. Alto padrão. Dinâmica imobiliária.

Resumen: Este artículo tiene como objetivo entender cómo el barrio Ecoville se levantó y cómo esta área se incorporó a la dinámica del sector inmobiliario a través de la construcción de edificios residenciales de alto nivel en la última década (2001-2011). La cuestión central de este trabajo es comprender cuáles son las motivaciones y las articulaciones entre los agentes implicados que guiaron el crecimiento del antiguo Conector 5, hoy llamado Ecoville, y cuáles los factores que determinan su crecimiento vertical y valoración. La elección de Ecoville justifica por ser el área de mayor interés del mercado inmobiliario en Curitiba, cuenta con la mayor oferta de inmuebles para la venta y terrenos para la construcción. En este sentido, hizo una breve reseña histórica del surgimiento y de la valoración del Ecoville. Más tarde, a partir dos datos obtenidos a través de investigación de campo fueron fechos tabla y mapas acerca da la área de investigación.

Palabras Clave: Ecoville. Dinámica Inmobiliaria. Alto Estándar.

1 O presente artigo é parte das reflexões iniciais da tese de doutorado que está em fase de elaboração e, portanto, os resultados apresentados são preliminares. Programa de Pós-Graduação em Geografia da Universidade Estadual de Maringá - PR. 


\begin{abstract}
This article aims to understand how did the Ecoville appeared and how this area was incorporated into the real estate dynamics through the construction of high standard residential buildings in the last decade (2001-2011). The central problem of this paper is to understand which are the interests and the relations among the actors involved in the guidance of the growth of the old Conectora 5, now called Ecoville, and what factors determined its verticalization and enhancement. The choice of the Ecoville for case study is justified for the great interest the real estate market of Curitiba has in the area, since it has the largest supply of properties for sale and land for construction. In this sense, a brief historical review of the appearance and enhancement of the Ecoville is presented. Afterwards, based on data obtained through field research, tables and maps were elaborated about the researched area.
\end{abstract}

Keywords: Ecoville. High standard. Real estate dynamics.

\title{
INTRODUÇÃO
}

O presente artigo tem como objetivo entender como surgiu o Ecoville e como essa área foi incorporada à dinâmica imobiliária por intermédio da construção de edifícios residenciais de alto padrão ${ }^{2}$ na última década (2001-2011). A propósito, deve-se registrar que nossa pesquisa elege a abordagem intraurbano de Curitiba, ou seja, a nós interessa entender apenas uma porção do espaço urbano de Curitiba, denominado de Ecoville.

Para tanto, nos apoiamos nos trabalhos de Villaça (2001), Moura e Firkowski (2001), Sánchez (2003), Firkowski (2007/2009), Pilotto (2010), Polucha (2010), e nos documentos do Instituto de Pesquisa e Planejamento Urbano de Curitiba (IPPUC) (1975/1980/2007), no Perfil Imobiliário ${ }^{3}$ (2010/2011), em entrevistas aos construtores e incorporadores, na Associação dos Dirigentes das Empresas do Mercado Imobiliário (ADEMI-PR), entre outros.

A problemática central deste artigo é entender quais os interesses e as articulações entre os agentes envolvidos que nortearam o crescimento da antiga Conectora 5, hoje denominada de Ecoville, e quais fatores determinaram a verticalização e valorização desta área. A escolha do Ecoville para estudo de caso justifica-se por ser a área de maior interesse do mercado imobiliário de Curitiba.

Com a finalidade de estabelecer as bases teóricas para a compreensão de quando e como surgiu o Ecoville, e por que essa área foi ocupada preferencialmente por edifícios

2 Não existe um consenso sobre o conceito de alto padrão, portanto, no contexto deste artigo consideramos os seguintes critérios para que um edifício residencial seja classificado como alto padrão: localização, padrão construtivo e o elemento clube. Numa primeira abordagem, alto padrão é aquele imóvel que custa acima de R\$600.000,00, com localização privilegiada, com grande área privativa e acabamentos de excelência. A rigor, esses empreendimentos apresentam um novo conceito de moradia: o conceito de "condomínio clube" (ADEMI-PR, 2011, p. 68). Em outras palavras, o conceito de alto padrão refere-se a um estilo, a um padrão de uniformidade e de homogeneidade que, quando aplicado a um imóvel, expressa sofisticação, requinte e distinção.

3 A Associação dos Dirigentes e Empresários do Mercado Imobiliário do Paraná (Ademi-PR) elabora e divulga todos os anos uma pesquisa de mercado intitulada de Perfil Imobiliário, que apresenta um panorama do setor imobiliário de Curitiba, bairro a bairro. Esse estudo é realizado em parceria com construtores, arquitetos, corretoras, engenheiros, imobiliárias, profissionais do setor e com entidades de pesquisa como o Instituto BRIDI, empresa que atua nas atividades de pesquisa de mercado e opinião, e a Bureau de Inteligência Corporativa (Brain), empresa especializada em serviços de consultoria em inteligência corporativa (ADEMI-PR, 2010). 
residenciais verticais de alto padrão, iniciamos as discussões com um breve resgate histórico da ocupação e expansão dessa área, a fim de contextualizar e inserir a área de pesquisa, localizada na porção Oeste da cidade de Curitiba (PR). E, por fim, sistematizamos em forma de tabela e mapas os dados obtidos a partir da investigação de campo sobre as principais características desses edifícios de alto padrão.

\section{MATERIAIS E MÉTODOS}

No que se refere à metodologia de pesquisa, foram utilizados dois procedimentos. O primeiro constou de procedimentos operacionais, tais como os trabalhos empíricos, a análise de obras referentes ao tema, a sistematização das informações primárias e secundárias. O segundo se configurou na metodologia de análise através do diálogo com autores que se dedicaram ao tema, constituindo-se os referenciais teórico-metodológicos. Após o levantamento bibliográfico e análise da bibliografia, incluídos os trabalhos a respeito do tema para a cidade de Curitiba, foram realizadas atividades de campo com entrevistas com construtoras e incorporadoras, com a Secretaria Municipal de Urbanismo de Curitiba (Setor de Alvarás), com o Departamento de Controle de Edificações, com o Instituto de Pesquisa e Planejamento Urbano de Curitiba (Ippuc), em três setores (Banco de Dados, Uso do Solo e Setor de Monitoração), e por fim com a assessoria de imprensa da Ademi-PR. A partir dos dados obtidos, confeccionou-se a tabela 1 com as principais características dos edifícios de apartamentos construídos no Ecoville entre os anos de 2001 e 2011, recorte temporal desta pesquisa. Após a análise dos dados foram elaborados três cartogramas, o primeiro com a localização das Vias Conectoras, o segundo mapa apresenta a distribuição espacial dos edifícios na área de estudo e o terceiro mapa mostra as construtoras que têm edifícios executados no Ecoville.

\section{RESULTADOS E DISCUSSÕES}

Antes de tudo, faz-se necessário delimitar o Ecoville ou a região do Ecoville. ${ }^{4}$ Consideramos que essa discussão é extremamente relevante, pois a falta de precisão em definir a área de estudo pode trazer leituras e interpretações equivocadas. Afinal, o que seria o Ecoville? Um bairro? Uma região? Um projeto imobiliário? Deve-se frisar que a delimitação do Ecoville é rica em controvérsias, entretanto apresentamos a seguir as opiniões de pesquisadores que desenvolveram trabalhos sobre essa temática, dos agentes do mercado imobiliário e de órgãos públicos municipais de Curitiba sobre a delimitação da área do Ecoville.

4 O conceito de "região" é polissêmico, a começar pela grande amplitude que a noção adquiriu no senso comum. Não temos aqui a intenção de fazer uma discussão teórico-conceitual sobre o termo, apenas esclarecer que, quando citado neste artigo, o se significado corresponde a uma região homogênea, a um determinado espaço geográfico que guarda características comuns, as quais são distintas daquelas ao seu redor. 
Para Polucha (2010) o Ecoville é o nome dado por incorporadores imobiliários em meados da década de 1990 à Conectora 5, Eixo Estrutural ${ }^{5}$ executado no início da década de 1980, que por sua vez foi planejado na década de 1970, como parte do projeto da Cidade Industrial de Curitiba (CIC). Numa estratégia de marketing o mercado imobiliário passou a denominar essa região localizada no bairro Mossunguê de Ecoville.

Compartilhando da mesma opinião de Polucha (2010), a Incorporada Thá (2011) considera:

Uma região nobre, arborizada, tranquila e em constante desenvolvimento. Assim é o Ecoville, em Curitiba. Localizado na região Oeste da cidade, vizinho do Bigorrilho, Campina do Siqueira, Orleans, Campo Comprido e Santo Inácio, o bairro, antes conhecido por suas chácaras e grandes áreas verdes, tem o nome Mossunguê. Mas, com a explosão imobiliária dos anos 90 e o desenvolvimento da região, o bairro também passou a ser chamado Ecoville (THÁ INCORPORADORA, 2011).

Na mesma vertente de raciocínio, Pilotto (2010) argumenta que:

O Ecoville foi o último 'filão' imobiliário de edifícios residenciais de Curitiba. Tratase do bairro Mossunguê, apelidado de Ecoville, uma continuação do Setor Estrutural Oeste, onde foi criada a Zona Nova de Curitiba em 1994 (Decreto $n^{\circ}$ 901/94). A verticalização no Ecoville foi intensa nas décadas de 1990 a 2000, bem como o desenvolvimento imobiliário da região, que além dos edifícios residenciais de alto padrão, contou com a instalação de diversos serviços ligados às camadas de alta renda (PILOTTO, 2010, p. 64).

Contrapondo a definição dos autores acima citados, para a (ADEMI-PR, 2011) o Ecoville não é apenas o bairro Mossunguê, e sim uma área formada por um conjunto de bairros.

Assim, para se definir a região Ecoville Champagnat, foi realizada a junção de cinco bairros: Bigorrilho, Campina do Siqueira, Campo Comprido, Mercês e Mossunguê. Cabe esclarecer que essa junção de bairros justifica-se pela homogeneidade entre os bairros e perfis dos imóveis (ADEMI-PR, 2011, p. 63).

Por sua vez, o Instituto de Pesquisa e Planejamento Urbano de Curitiba (Ippuc) afirma que Curitiba tem 75 bairros, distribuídos em nove regionais, ${ }^{6}$ e que não existe, oficialmente, nenhum bairro chamado Ecoville. O que existe é uma junção de três bairros (Mossunguê, Campina do Siqueira e Campo Comprido), próximos um do outro, perten-

5 Os Setores Estruturais, ou Eixos Estruturais, são faixas do zoneamento onde é permitida a verticalização e que acompanham eixos viários no sentido norte, oeste e leste-sudoeste. Eles foram criados nos anos de 1960 (Lei n. 2.828/66) e sua implantação, que envolveu a execução de uma série de obras (sistema viário e transporte coletivo), foi realizada nos anos de 1970 e 1980. Ao analisar a verticalização dos Setores Estruturais, conclui-se que, ainda que a legislação urbanística sempre tenha tratado os Setores Estruturais da mesma maneira - com o mesmo sistema de transporte, sistema viário e parâmetros de uso e ocupação do solo -, a ocupação não foi uniforme ao longo deles (PILOTTO, 2010, p. 170).

6 As regionais de Curitiba são espécies de subprefeituras encarregadas dos bairros de cada uma das nove regiões em que Curitiba está subdividida administrativamente. As Administrações Regionais acompanham as ações das secretarias municipais dentro de suas áreas-limites, e participam da organização de seus serviços. Fornecem à comunidade informações e atendimentos, dentro dos limites de sua competência, ou os encaminham aos órgãos competentes. As regionais são: Bairro Novo, Boa Vista, Boqueirão, Cajuru, CIC, Matriz, Pinheirinho, Portão e Santa Felicidade (IPPUC, 2007). 
centes à Regional de Santa Felicidade ${ }^{7}$ e localizados na porção Oeste da cidade de Curitiba, denominada pelos agentes do mercado imobiliário de Ecoville, área direcionada à população de alta renda (DADOS DE CAMPO, 2012).

Nesse sentido, não existe oficialmente nenhum bairro chamado Ecoville em Curitiba Diante dessa constatação, propomos uma hipótese sobre a delimitação dessa área. Nossa hipótese está fundamentada nas evidências empíricas obtidas na investigação de campo, que será analisada neste artigo mais à frente, e também nas reflexões de (FIRKOWSKI, 2009, p. 53), que considera "[...] o Ecoville, localizado no interior da Zona Nova de Curitiba, ${ }^{8}$ um prolongamento do Setor Especial Estrutural, ${ }^{9 \prime \prime}$ isto é, o Ecoville é um prolongamento da Conectora 5.

Sendo assim, nossa hipótese considera como Ecoville uma pequena porção dos bairros (Campina do Siqueira, Campo Comprido, Mossunguê e Cidade Industrial), que são compostos pelo eixo trinário ${ }^{10}$ das três principais ruas (Professor Pedro Viriato Parigot de Souza, Deputado Heitor Alencar Furtado e Monsenhor Ivo Zanlorenzi). Entretanto, consideramos que a delimitação físico-territorial do Ecoville proposta neste trabalho é provisória, pois à medida que o capital imobiliário precisa de novos terrenos para construção de edifícios residenciais de alto padrão, áreas próximas, como por exemplo o bairro Bigorrilho e Mercês, vão sendo incorporados ao Ecoville e comercializados sob esse nome. A figura 1 mostra em destaque a Conectora 5 composta pelo sistema trinário, uma das ligações entre o bairro Cidade Industrial de Curitiba (CIC) e o centro da cidade. É importante observar que o eixo estrutural corta no sentido Leste-Oeste parte dos bairros Mossunguê, Campina do Siqueira e a parte norte do bairro Campo Comprido.

Vale registrar que, ao longo do eixo estrutural e nas vias paralelas, localizam-se não apenas os edifícios residenciais de alto padrão, mas também edifícios comerciais e de serviços, casas de alvenaria e sobrados. Importantes empreendimentos foram construídos ao longo da Conectora 5, como podemos ver na legenda da (Figura 1). No Mossunguê localizam-se o Park Shopping Barigui e o Hipermercado Carrefour, representados respectivamente pelas letras B e C. Os terminais de transporte coletivos urbano localizam-se no Campo Comprido, representados na legenda pela letra A, e no Campina do Siqueira, representados pela letra $\mathrm{D}$. Após os esclarecimentos sobre a localização da área de estudo, passemos a entender a origem da Conectora 5.

7 A Regional Santa Felicidade é composta por 14 bairros: Butiatuvinha, Campina do Siqueira, Campo Comprido, Cascatinha, Cidade Industrial, Lamenha Pequena, Mossunguê, Orleans, Santa Felicidade, Santo Inácio, São Braz, São João, Seminário e Vista Alegre. Com uma população total de 155.794 habitantes (CENSO, 2010), ocupa uma área de 6.529 hectares (IPPUC, 2010).

8 O Setor Especial Nova Curitiba (SE-NC), assim como outros setores especiais, compreendem áreas para as quais são estabelecidas ordenações especiais de uso e ocupação do solo, considerando a sua localização, função ou ocupação existente e/ou projetada. Possui lote mínimo de $450 \mathrm{~m}^{2}$ e coeficiente de aproveitamento de duas vezes a área do lote. A altura máxima da edificação é livre (IPPUC, 2007, p. 28).

9 O Setor Especial Estrutural (SE) consiste em áreas de expansão do centro tradicional e como corredores comerciais, de serviços e de transportes. São essas áreas os principais eixos de crescimento da cidade e elas têm como suporte o sistema trinário de circulação. O Setor Especial Estrutural possui parâmetros específicos de ocupação, sendo um deles a implantação do plano massa (quando o imóvel está voltado para a via central), que consiste basicamente em um embasamento com galeria comercial, que garante a continuidade da testada e ampliação da área de passeio (galeria coberta). Outro parâmetro é o da altura livre para usos como habitação coletiva, o que incentiva o adensamento (IPPUC, 2007, p. 28).

10 Entendem-se como vias estruturais o sistema trinário composto por uma via central e duas vias externas, sendo a via central aquela que contém a canaleta para o transporte de massa e as pistas lentas para atendimento às atividades lindeiras e sendo as vias externas as ruas paralelas sem sentido único de tráfego, destinadas ao tráfego contínuo de automóveis (DECRETO n. 399/80, art. $1^{\circ}$ ). (PILOTTO, 2010, p. 190). 
Figura 1: Mapa das Vias Conectoras, Ecoville, Curitiba (PR)

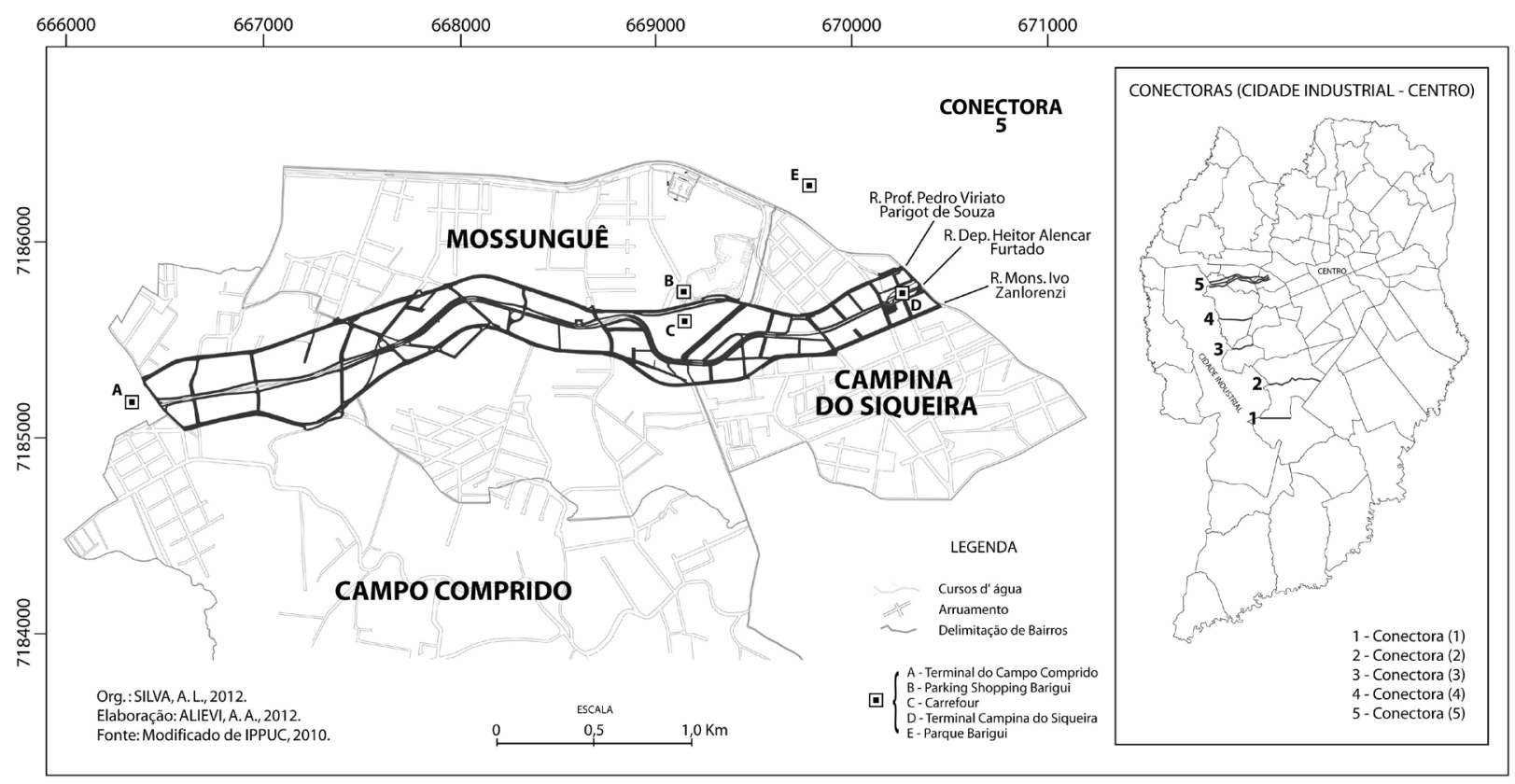

Fonte: IPPUC, 2010

O Ecoville tem sua origem ligada ao projeto do eixo viário denominado Conectora 5, elaborado na década de 1970, que previa a transformação de uma área praticamente desabitada em uma nova frente de expansão urbana. No início da década de 1980 essa obra foi concluída, porém sua ocupação só teve início na década de 1990. A partir do início da exploração imobiliária a área da Conectora 5 recebeu o nome de Ecoville e sua ocupação foi totalmente direcionada para as camadas de alta renda, tornando-se uma das regiões mais nobres de Curitiba (POLUCHA, 2010).

Não se pode separar essa área do planejamento industrial da cidade de Curitiba, desde quando, em 1963, a Companhia de Desenvolvimento Econômico do Paraná (Codepar) elaborou o estudo Industrialização do Paraná - Curitiba e Ponta Grossa, que defendia que o impulso à industrialização seria mais efetivo se os investimentos fossem concentrados em um único polo. De acordo com o estudo, o melhor local para instalação desse polo era a região de Curitiba. A escolha da localização da CIC na porção Oeste da cidade levou em conta a topografia adequada, disponibilidade de água e facilidade de drenagem (IPPUC, 1975).

O planejamento da urbanização da Cidade Industrial de Curitiba (CIC), onde hoje se localiza o Ecoville, tinha como proposta uma ocupação do espaço que integrasse as indústrias ao núcleo urbano existente, interligando toda essa área por meio das Vias Conectoras ${ }^{11}$ e executando áreas habitacionais destinadas à habitação social. Essa proposta garantiria acessibilidade e moradia para a mão de obra atraída pela industrialização (POLUCHA, 2010).

11 As Vias Conectoras são vias de conexão entre a malha viária urbana existente e a CIC. Cada conectora é composta por 3 vias: 2 de tráfego rápido em sentidos únicos e a central, de tráfego lento, segundo a mesma concepção do sistema trinário das vias estruturais. A faixa compreendida entre as vias componentes das Conectoras é destinada à construção de conjuntos habitacionais, de alta densidade, bem como à fixação de atividades terciárias (IPPUC, 1975, não paginado). 
Pouco antes do início das obras foi elaborado o Projeto Nova Curitiba, ${ }^{12}$ cujo objetivo era a aquisição de terras por parte do poder público para a promoção de habitação popular (POLUCHA, 2010). Nesses termos, as obras de implantação da Cidade Industrial de Curitiba (CIC) foram iniciadas em 1974, sua inauguração oficial ocorreu em 1975, e a infraestrutura completa foi concluída em 1979. A implantação da CIC ocorreu de acordo com o modelo desenvolvimentista, ou seja, tendo o Estado como principal agente indutor (POLUCHA, 2010). Um dos objetivos da CIC era induzir a expansão urbana de Curitiba para o Oeste. Os principais elementos estruturadores dessa urbanização seriam as áreas habitacionais e as Vias Conectoras.

A princípio, de acordo com o que havia sido originalmente planejado, não deveria haver significativos diferenciais de acessibilidade, pois toda a área Oeste teria fácil acesso ao núcleo urbano consolidado através das Vias Conectoras. Entretanto, já se podia antever que a Conectora 5 teria uma melhor acessibilidade. "Além de estar localizada mais próxima da área central da cidade que as demais Vias Conectoras, ela seria o prolongamento do eixo estrutural Oeste. Não era difícil, portanto, prever que a Conectora 5 teria uma valorização maior" (POLUCHA, 2010, p.100).

Na perspectiva de Polucha (2010), outras intervenções estatais ampliaram ainda mais essa expectativa de valorização da Conectora 5. No início da década de 1970 foi implantado o Parque Barigui. Sua localização era muito próxima de onde futuramente seria executada a Conectora 5. A implantação do Parque Barigui "[...] acrescentou aos imóveis localizados na zona Oeste de Curitiba uma valorização jamais esperada em tão curto prazo de tempo" (IPPUC, 1980, p. 21). Mas o fator que influiu decisivamente na valorização da Conectora 5 foi o fato de ela ter sido a única Via Conectora integralmente executada. "Isso aumentou acentuadamente os diferenciais de acessibilidade em relação às demais áreas da zona Oeste, tornando a Conectora 5 uma localização extremamente privilegiada." (POLUCHA, 2010, p.101).

[...] O bairro crescia com a explosão econômica e imobiliária. No final dos anos de 1970 e início dos anos 1980, o Bigorrilho (bairro por onde passa o eixo estrutural Oeste) começava a passar pelas grandes mudanças que o caracterizam hoje. A alteração da lei de zoneamento e uso do solo aprovada pela Câmara Municipal chamaram a atenção das imobiliárias e construtoras. As ruas ganhavam pavimentação e muitos edifícios surgiam à paisagem onde antes predominavam os campos e as casas simples (FENIANOS, 1997, p. 28).

Em 1974 foi realizado um estudo para definir como se daria a ocupação das Vias Conectoras.

Seguindo os princípios determinados pelo planejamento inicial do Ippuc, foi elaborado o Plano Massa das Vias Conectoras da Cidade Industrial de Curitiba. Esse plano propunha uma ocupação diversificada, com uso habitacional, comercial e de

12 A construção da Nova Curitiba, um bairro modelo dotado de todos os serviços urbanos, inclusive transporte de massa, será um exemplo da total integração das funções urbanas. A Nova Curitiba será implantada na Conectora 5 (Ramal Oeste da Estrutura Norte), dotada de toda infraestrutura básica, habitação, equipamentos comunitários e serviços de apoio. O setor comercial terá um desenvolvimento linear ao longo de ambos os lados da via central, interligados entre sim por passarelas. A moradia, em seus diversos níveis, se integra ao setor comercial, formando vizinhanças diversificadas (IPPUC, 1980, p. 10). 
serviços, em uma paisagem que alternava blocos de edifícios de pequena altura com um adensamento construtivo maior nos locais previstos para pontos de parada de ônibus (POLUCHA, 2010, p. 71).

De acordo com Polucha (2010), o primeiro edifício construído na Conectora 5 foi em 1993, porém a ocupação efetiva só se consolidou a partir do ano 2000. Na administração de Roberto Requião (1985-1988), foi aprovado o decreto municipal n. 279, em 1987, alterando novamente os parâmetros construtivos da Conectora 5. A principal mudança foi permitir altura livre para construção de edifícios com um coeficiente de aproveitamento igual a dois. A legislação urbanística foi determinante para o tipo de ocupação desses terrenos da Conectora 5. A permissão de incorporação em lotes com mais de 5.000 $\mathrm{m}^{2}$ e a exigência de amplos recuos nos edifícios direcionaram um determinado tipo de empreendimento: edifícios de alto padrão, isolados em terrenos de grande dimensão, geralmente com muita área verde (POLUCHA, 2010).

Segundo Firkowski (2009) a legislação urbanística da área foi alterada por pressão dos incorporadores imobiliários, que queriam construir edifícios de alto padrão e com mais pavimentos do que a legislação permitira (6 pavimentos). "Eles se anteciparam na aquisição dos lotes baratos e pouco valorizados existentes no local, reservando áreas extensas para expansão futura" (FIRKOWSKI, 2009, p. 54).

O primeiro edifício construído no Ecoville foi o Residencial Palais Lac Leman, da Helvetia Construtora e Incorporadora Ltda. Tratava-se de um edifício residencial de alto padrão, com 24 pavimentos e 21 apartamentos de $820 \mathrm{~m}^{2}$, localizado em uma área verde de 13 mil m² (POLUCHA, 2010). “[...] na fase inicial, foram construídos quatro edifícios, um de cada construtora (Thá, Moro, Hauer, Casa), com apartamentos entre 117 e 635 m² (FIRKOWSKI, 2009, p. 54).

Numa estratégia de marketing as qualidades ambientais foram utilizadas para garantir status diferenciado aos empreendimentos do Ecoville. Nesse sentido, um aspecto central da introdução desse discurso ecológico foi sua associação a uma estratégia de City-Marketing, em que os atributos ambientais da cidade são pensados a partir de seu valor de troca, e não a partir de seu valor de uso. A natureza é utilizada para valorizar o espaço (SÁNCHEZ, 2003).

Outros empreendimentos também contribuíram para a valorização do Ecoville. No ano de 2000 foi construído o campus da Universidade Positivo em uma área de $410.000 \mathrm{~m} 2$, parte de um complexo que abriga, além do espaço acadêmico, um teatro e um centro de convenções e dois auditórios, respectivamente com 2.400 lugares e 714 lugares. Um hotel com 120 apartamentos será construído nos próximos anos e está também em construção o novo campus da Universidade Tecnológica Federal do Paraná. Em 2003 foi inaugurado o Park Shopping Barigui, o maior da cidade até então, com uma área de 108.000 m2. Localizado no início da Conectora 5, é um dos centros de compras mais sofisticados de Curitiba (POLUCHA, 2010).

Para Pilotto (2010, p. 64), “[...] a localização da maior parte dos shoppings de Curitiba, especialmente aqueles destinados às camadas de alta renda, foram construídos predominante no setor Oeste da cidade." 
[...] trata-se, portanto, de um importante reduto da classe média alta e alta, que dispõe de padrões diferenciados de ocupação do solo, com recuos avantajados entre as construções e uma série de equipamentos de lazer (quadras, piscinas, áreas verdes, etc.), traduzindo-se, verdadeiramente, no nome dado à iniciativa, qual seja, Ecoville, ou "cidade ecológica" (FIRKOWSKI, 2009, p.54).

A estratégia de venda do mercado imobiliário associou a existência de grandes áreas verdes na Conectora 5 à imagem de Curitiba como "capital ecológica".

De acordo com o diretor da Thá Imobiliária, que participou da elaboração do projeto de ocupação da Nova Curitiba, as construtoras investiram aproximadamente US\$ 200 mil numa campanha de marketing na época do lançamento do Ecoville (POLUCHA, 2010, p. 128).

Tendo em vista essa valorização, o setor imobiliário procurou lançar empreendimentos que possibilitassem o melhor aproveitamento econômico dos terrenos.

Esses eixos foram contemplados com ampla rede de infraestrutura e serviços e controlados por uma legislação de uso do solo que, voltada para incentivar o seu adensamento habitacional, acabou por valorizar os imóveis lindeiros, inibir a ocupação e criar áreas nobres permeadas por grandes vazios (MOURA; FIRKOWSKI, 2001, p. 212).

Outro elemento importante para a valorização do Ecoville foi a questão da acessibilidade. $\mathrm{O}$ acesso ao centro de Curitiba foi garantido por meio dos Setores Estruturais, já que, além do transporte coletivo, eles são formados pelas vias rápidas estruturais, que ligam os bairros ao centro e que se destinam ao transporte individual de passageiros. "[...] esse desenho favoreceu o aprimoramento da circulação do transporte individual das classes médias residentes em seu trajeto e, ao mesmo tempo, o transbordo das massas nos terminais de ligação com as periferias." (MOURA; FIRKOWSKI, 2001, p. 212).

De acordo com Villaça (2001), a produção de valor da terra está diretamente ligada à acessibilidade ao sistema urbano.

Assim, como toda a circulação urbana de Curitiba estava organizada em torno dos eixos estruturais, estes se tornaram localizações privilegiadas. Isso causou a elevação do preço da terra nessas áreas, fazendo com que os eixos estruturais se tornassem também eixos de valorização imobiliária (POLUCHA, 2010, p. 35).

A partir do que foi acima exposto, sobre quando e como surgiu o Ecoville, passemos agora a localizar e identificar os edifícios residenciais construídos nessa porção do espaço. Para a elaboração da tabela 1, foram realizadas atividades de campo no IPPUC, em três setores: Banco de Dados, Uso do Solo e Setor de Monitoração.

A tabela 1 apresenta as principais características dos edifícios de apartamentos construídos no Ecoville entre os anos de 2001 e 2011, recorte temporal desta pesquisa. 
Tabela 1 - Edifícios construídos no Ecoville, Curitiba, PR: 2001 a 2011

\begin{tabular}{|c|c|c|c|c|c|c|}
\hline CÓDIGO & EDIFÍCIO & CONSTRUTORA & PAV. & TORRE & $\begin{array}{c}\mathrm{N}^{\circ} \mathrm{DE} \\
\text { UNIDADES }\end{array}$ & $\begin{array}{c}\text { ANO DE } \\
\text { CONCLUSÃO } \\
\end{array}$ \\
\hline 1 & Pierrot & Moro Construções & 21 & 1 & 38 & 2001 \\
\hline 2 & Millenium & Hauer Construções & 22 & 1 & 40 & 2001 \\
\hline 3 & Portal do Ecoville & Irmãos Thá S.A. & 30 & 1 & 56 & 2001 \\
\hline 4 & Tom e Vinícius & Moro Construções & 13 & 2 & 35 & 2001 \\
\hline 5 & San Pelegrino & $\begin{array}{l}\text { Construtora } \\
\text { Equilíbrio } \\
\end{array}$ & 8 & 2 & 32 & 2002 \\
\hline 6 & Green Life & \begin{tabular}{|c|} 
Jota Ele Construções \\
Civis
\end{tabular} & 15 & 1 & 28 & 2002 \\
\hline 7 & Ecoville Tower & \begin{tabular}{|c|}
$\begin{array}{c}\text { Helio Walter } \\
\text { Yamaguti }\end{array}$ \\
\end{tabular} & 16 & 1 & 15 & 2002 \\
\hline 8 & L'Excellence & Hugo Peretti & 20 & 2 & 76 & 2002 \\
\hline 9 & Four Seasons & Hauer Construções & 25 & 1 & 23 & 2004 \\
\hline 10 & Rio Tevere & Irmãos Thá S.A. & 22 & 1 & 40 & 2004 \\
\hline 11 & Ilhas Baleares & Bonet Construtora & 22 & 2 & 41 & 2004 \\
\hline 12 & Terrasse Ecoville & Terrasse & 27 & 1 & 98 & 2004 \\
\hline 13 & $\begin{array}{l}\text { Residencial } \\
\text { Camões }\end{array}$ & MRV Engenharia & 3 & 2 & 6 & 2005 \\
\hline 14 & Mont Vert & Irmãos Thá S.A. & 23 & 1 & 42 & 2006 \\
\hline 15 & Le Corbusier & $\begin{array}{c}\text { Plaenge } \\
\text { Empreendimentos }\end{array}$ & 24 & 1 & 46 & 2006 \\
\hline 16 & San Raphael & Harbor & 23 & 1 & 22 & 2006 \\
\hline 17 & Ville de Valence & Terrasse & 21 & 1 & 40 & 2007 \\
\hline 18 & Manhattan & Valor & 29 & 1 & 28 & 2007 \\
\hline 19 & Poty Lazzaroto & $\begin{array}{c}\text { Plaenge } \\
\text { Empreendimentos }\end{array}$ & 30 & 1 & 56 & 2007 \\
\hline 20 & Euro Building & Vectra Construtora & 24 & 1 & 23 & 2007 \\
\hline 21 & Tannat Ecoville & $\begin{array}{l}\text { Construtora } \\
\text { Equilíbrio }\end{array}$ & 8 & 2 & 16 & 2008 \\
\hline 22 & Lasar Segall & $\begin{array}{c}\text { Plaenge } \\
\text { Empreendimentos }\end{array}$ & 20 & 1 & 76 & 2008 \\
\hline 23 & New Edge & Dória & 21 & 1 & 32 & 2008 \\
\hline 24 & Belluno & Bonet Construtora & 30 & 1 & 29 & 2008 \\
\hline 25 & Santos Dumont & Hugo Peretti & 17 & 2 & 62 & 2008 \\
\hline 26 & $\begin{array}{l}\text { Le Jardim des } \\
\text { Tulleries } \\
\end{array}$ & PIL & 24 & 1 & 21 & 2008 \\
\hline 27 & Avant Garden & Irmãos Thá S.A. & 27 & 1 & 48 & 2008 \\
\hline 28 & Royal Club & $\mathrm{LN}$ & 24 & 1 & 44 & 2009 \\
\hline 29 & Hera Garden & Hestia & 8 & 1 & 14 & 2009 \\
\hline 30 & Belvedere & $\begin{array}{c}\text { Plaenge } \\
\text { Empreendimentos }\end{array}$ & 23 & 1 & 44 & 2009 \\
\hline 31 & Vilanova Artigas & $\begin{array}{c}\text { Plaenge } \\
\text { Empreendimentos }\end{array}$ & 20 & 1 & 76 & 2009 \\
\hline 32 & $\begin{array}{l}\text { Alfredo } \\
\text { Andersen }\end{array}$ & $\begin{array}{c}\text { Plaenge } \\
\text { Empreendimentos }\end{array}$ & 23 & 1 & 46 & 2010 \\
\hline 33 & The Royal Plaza & $\begin{array}{c}\text { Construtora } \\
\text { Andrade Ribeiro }\end{array}$ & 26 & 2 & 26 & 2010 \\
\hline 34 & $\begin{array}{c}\text { Cenarium } \\
\text { Ecoville }\end{array}$ & PDG Construtora & 9 & 3 & 16 & 2010 \\
\hline
\end{tabular}




\begin{tabular}{c|c|c|c|c|c|c}
\hline CÓDIGO & EDIFÍ́CIO & CONSTRUTORA & PAV. & TORRE & $\begin{array}{c}\text { No DE } \\
\text { UNIDADES }\end{array}$ & $\begin{array}{c}\text { ANO DE } \\
\text { CONCLUSÃO }\end{array}$ \\
\hline 35 & Breeze Ecoville & $\begin{array}{c}\text { Construtoras Rossi } \\
\text { e Thá }\end{array}$ & 4 & 4 & 21 & 2010 \\
\hline 36 & Barolo & $\begin{array}{c}\text { Construtora } \\
\text { Equilíbrio }\end{array}$ & 10 & 3 & 16 & 2010 \\
\hline 37 & Garden Ecoville & Vanguard Home & 25 & 2 & 150 & 2010 \\
\hline 38 & Cecília Meireles & $\begin{array}{c}\text { Plaenge } \\
\text { Empreendimentos }\end{array}$ & 16 & 1 & 64 & 2011 \\
\hline 39 & Clarice Lispector & $\begin{array}{c}\text { Plaenge } \\
\text { Empreendimentos }\end{array}$ & 24 & 1 & 96 & 2011 \\
\hline 40 & Neo Garden & Construtora Gafisa & 22 & 2 & 144 & 2011 \\
\hline 41 & Alliance & Vértika & 27 & 1 & 28 & 2011 \\
\hline 42 & Terrasse Noveau & Terrasse & 12 & 1 & 36 & 2011 \\
\hline 43 & Platinum Tower & Ecoenge Construtora & 26 & 2 & 26 & 2011 \\
\hline 44 & Garden Parigot & Vanguard Home & 25 & 2 & 150 & 2011 \\
\hline
\end{tabular}

Fonte: Secretaria Municipal de Urbanismo. Instituto de Pesquisa e Planejamento Urbano de Curitiba (Ippuc), 2011. (Adaptado de POLUCHA, 2010, p. 131). Org.: Andresa Lourenço da Silva.

Nota: (1) Foi considerado como ano de conclusão o ano de expedição do Certificado de Vistoria de Conclusão de Obras (CVCO), emitido pela Prefeitura Municipal de Curitiba.

No período estabelecido da pesquisa foram identificados 44 edifícios de apartamentos construídos no Ecoville, a maioria acima de 20 pavimentos (andares), chegando até 30 pavimentos. Identificamos edifícios com 3, 4 e 8 pavimentos, mostrando, assim, que o Ecoville não é composto apenas por edifícios com torres altas. Entretanto, consideramos que existe uma variação média na altura dos edifícios entre 12 metros a 98 metros de altura. O número de unidades (apartamentos) em cada edifício varia entre seis e 150, não havendo um predomínio de unidades por edifício.

O ano de 2011 foi o com maior número de edifícios construídos no Ecoville, num total de sete edifícios, conforme indica a tabela 1. As construtoras e incorporadoras - Gafisa, LN Empreendimentos, Terrasse, Ecoenge Construtora e Vanguard Home entregaram nesse ano, cada uma, um empreendimento. Diferente dessa realidade, a Plaenge Empreendimentos entregou no ano de 2011 dois empreendimentos, os edifícios Cecília Meireles e Clarice Lispector, ambos localizados na Rua Deputado Heitor Alencar Furtado.

A partir da tabela 1 elaboramos o mapa onde localizamos e identificamos os edifícios de apartamentos construídos no Ecoville. A legenda da figura 2 foi organizada de forma hierárquica, levando em consideração o ano de conclusão de cada edifício, isto é, do edifício mais antigo para o mais recente. 
Figura 2: Localização dos edifícios no Ecoville, Curitiba (PR)

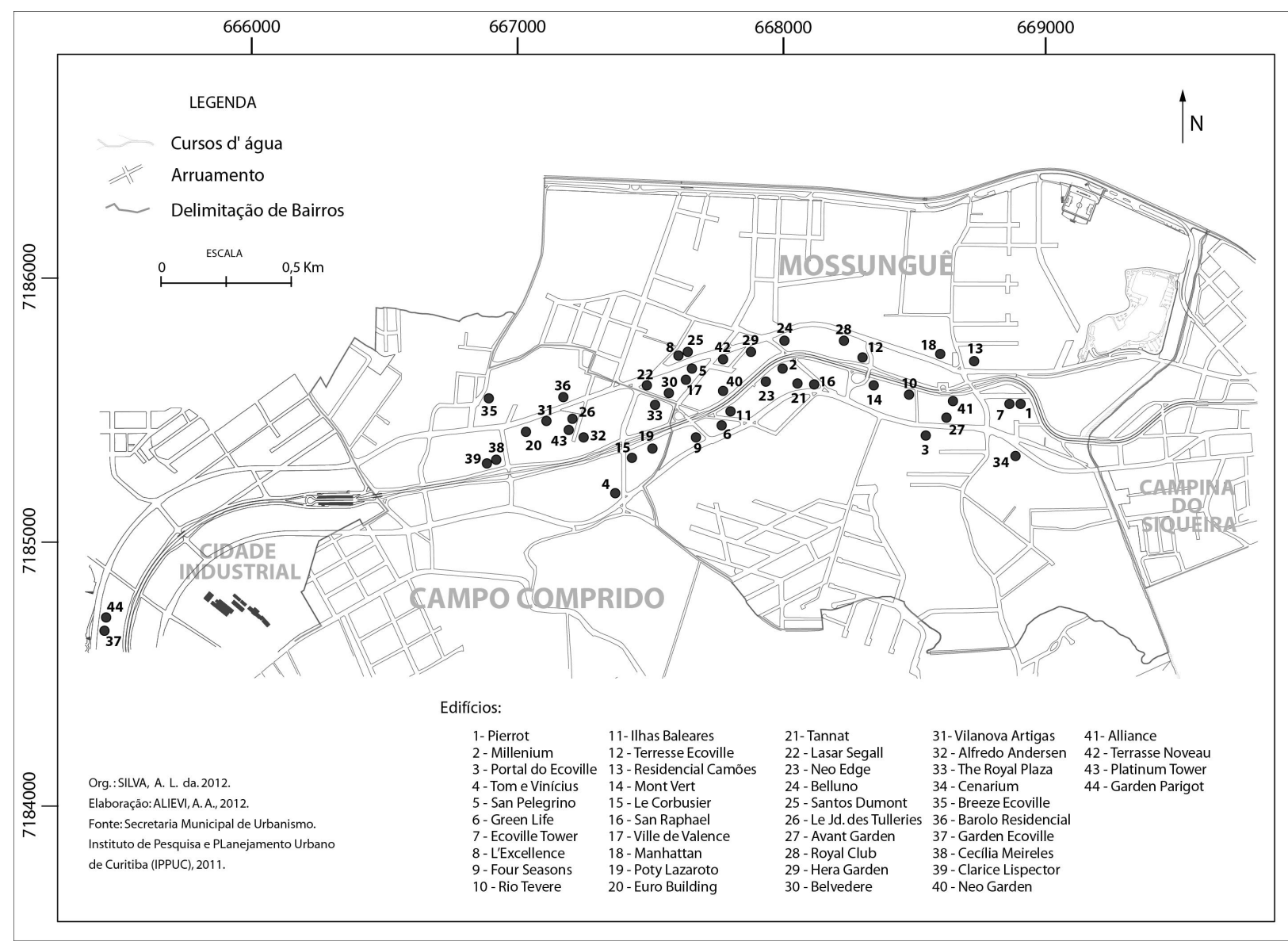

Fonte: IPPUC, 2011

Em relação à distribuição espacial dos edifícios, identificamos 12 edifícios construídos na Rua Deputado Heitor Alencar; dez edifícios construídos na Rua Professor Pedro Viriato Parigot de Souza; e cinco edifícios construídos na Rua Monsenhor Ivo Zanlorenzi, três principais ruas do Ecoville. Os outros 17 edifícios estão distribuídos nas ruas transversais a essas três ruas principais.

A partir do mapa podemos verificar a concentração dos edifícios no bairro Mossunguê e também na parte norte do bairro Campo Comprido, quase todos localizados nas três principais ruas do sistema trinário. É possível verificar forte concentração dos edifícios, com destaque à proximidade dos edifícios um do outro.

Em nossa investigação de campo verificamos que os edifícios localizados na Rua Professor Pedro Viriato Parigot de Souza são os que apresentam as torres mais altas e têm os apartamentos mais luxuosos do Ecoville. Quanto mais nos distanciamos do bairro Mossunguê em sentido ao bairro Campina do Siqueira menor o tamanho das torres dos edifícios, demonstrando, assim, que o Ecoville atende também a uma demanda por imóveis compactos com menor número de pavimentos.

Outra característica que merece destaque é o fato de que a Rua Professor Pedro Viriato Parigot de Souza concentra e centraliza as principais atividades de serviços e comér- 
cio, como, por exemplo, agência bancária, hipermercado, Shopping Center, posto de gasolina, centro de ensino superior, teatro e o centro de eventos, além de um pequeno centro comercial que oferece serviços como: lavanderia, pet shop, salão de beleza, lanchonete, padaria, entre outros. Nas outras duas ruas principais do Ecoville, Deputado Heitor Alencar Furtado e Monsenhor Ivo Zanlorenzi, encontramos também restaurantes, escolas municipais, escolas de idiomas, escolas de ensino fundamental particular, pronto atendimento de saúde (unidade de saúde pública), clínicas veterinárias, templos religiosos, terminais de transporte urbano, a Universidade Tecnológica Federal do Paraná/Campus Ecoville (UTFPR), clube social, entre outros estabelecimentos (DADOS DE CAMPO, 2012).

Retomando a hipótese inicial deste artigo, na qual consideramos como Ecoville a parte dos bairros Campina do Siqueira, Campo Comprido, Mossunguê e Cidade Industrial, que são compostos pelo eixo trinário das três principais ruas (Professor Pedro Viriato Parigot de Souza, Deputado Heitor Alencar Furtado e Monsenhor Ivo Zanlorenzi), partimos do seguinte raciocínio para confirmar nossa hipótese.

Quando propomos uma delimitação para o Ecoville, e argumentamos que essa definição é provisória, é porque nos apoiamos nas evidências da investigação de campo. Explicando melhor, ao mapearmos os edifícios construídos no Ecoville entre os anos de 2001 e 2011, observamos que muitos edifícios não estão localizados apenas no bairro Mossunguê, como afirma Polucha (2010), Pilotto (2010) e os agentes do mercado imobiliário que defendem essa ideia. Concordamos que o processo de construção dos edifícios iniciou-se no bairro Mossunguê, o qual concentra o maior número de edifícios (29 edifícios), como aponta a figura 2. Entretanto, podemos verificar que, dos 44 edifícios construídos no Ecoville, 13 estão no bairro Campo Comprido, 2 na Cidade Industrial. Diante desse mapeamento, podemos concluir que o Ecoville se estende além do bairro Mossunguê, confirmando assim nossa hipótese, de que o Ecoville é um prolongamento do eixo estrutural, como aponta (FIRKOWSKI, 2009) e que sua delimitação é provisória, sendo incorporadas outras áreas à medida que o mercado imobiliário precise de outros terrenos para a construção de suas obras.

Após a elaboração do mapa dos edifícios construídos no Ecoville, fizemos o levantamento das construtoras que têm edifícios executados nessa área. $\mathrm{O}$ mapa a seguir (figura 3) mostra a distribuição espacial das construtoras de acordo com o número de edifícios construídos no Ecoville. Cada construtora é acompanhada de um número, que corresponde ao nome do edifício. Identificamos 24 construtoras e incorporadoras no período da pesquisa.

A construtora com maior número de edifícios no Ecoville é a Plaenge Empreendimentos, num total de oito edifícios, que representa 5,75\% do mercado imobiliário do Ecoville. É importante frisar que antes do ano de 2001 a Plaenge não tinha nenhum edifício construído no nessa área. Em seguida vem a Thá incorporadora, com quatro edifícios construídos, representando 1,15\% do número de edifícios construídos da área de pesquisa. Entretanto, a Thá incorporadora tem dois edifícios construídos antes de 2001, período que antecede esta pesquisa. Levando em consideração esses dados, a Thá tem um total de seis edifícios construídos. Cabe destacar que essas duas incorporadoras são de capital local (paranaense). 
Figura 3: Localização das construtoras no Ecoville, Curitiba (PR)

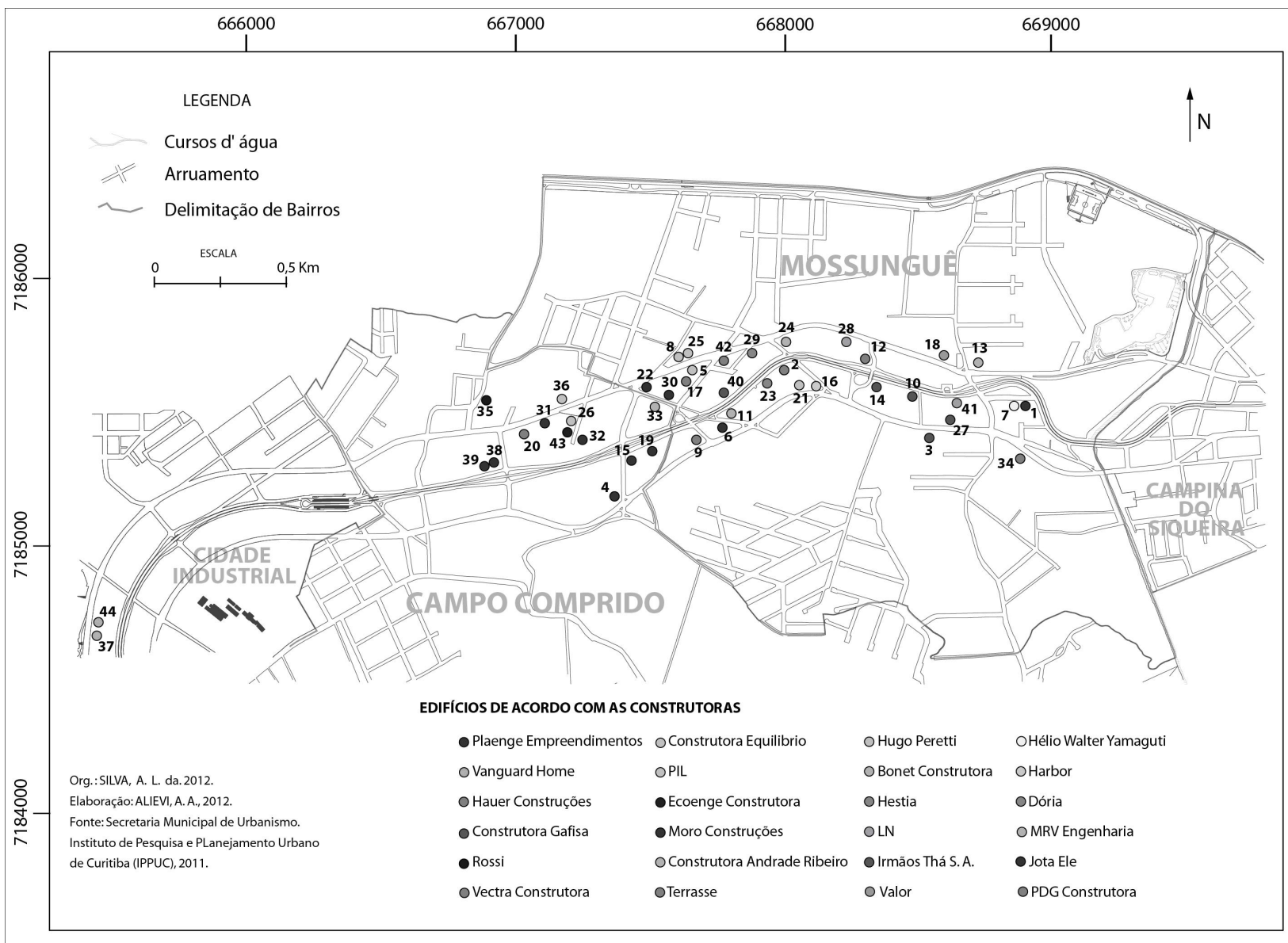

Fonte: IPPUC, 2011

\section{CONSIDERAÇÕES FINAIS}

Duas grandes questões traduzem a problemática central que foi desenvolvida neste artigo; primeiro identificando quais os interesses e as articulações entre os agentes envolvidos, que nortearam o crescimento da Conectora 5; segundo, como essa área foi incorporada à dinâmica imobiliária por intermédio da construção de edifícios residenciais de alto padrão.

Nosso percurso revela, portanto, que o Ecoville é uma área cuja valorização foi resultado direto do processo de planejamento urbano. A ideia de integrar os investimentos em infraestrutura a uma ocupação voltada para a população de baixa renda foi frustrada, pois o Programa Integrado de Habitação, Infraestrutura e Transporte não foi executado pelo Poder Público e o desenvolvimento da Conectora 5 seguiu um rumo diferente.

Não só o projeto habitacional e interesse social não foram efetivados, como nenhum outro tipo de habitação foi construído durante uma década (POLUCHA, 2010). Quando a ocupação ocorreu, foi voltada para as camadas de alta renda. Com isso o adensamento esperado e a indução da expansão urbana não se concretizaram. Portanto, consideramos que quem definiu a direção do crescimento da Conectora 5 foi uma coalizão de interes- 
$\operatorname{ses}^{13}$ de quem adquiriu terras e reteve seu uso por uma década. Isso produziu uma falsa escassez, que contribuiu para que a urbanização em Curitiba, e mais especificamente na CIC, ocorresse de maneira desigual (POLUCHA, 2010).

Entre os agentes envolvidos no processo de produção e valorização do Ecoville, destacamos em primeiro lugar o Estado, que viabilizou o desenvolvimento da Conectora 5 através da infraestrutura viária que deu acesso ao centro principal de Curitiba; em segundo lugar os promotores imobiliários, que anteciparam a compra de terrenos para a construção de seus empreendimentos e que exploraram o discurso de city marketing de Curitiba,; $\mathrm{e}$ por fim as classes de alta renda, que escolheram o Ecoville como área nobre para ocupação de moradias verticais de alto poder aquisitivo.

Retomando o questionamento inicial deste artigo, podemos concluir que o Ecoville não é um bairro, não é um projeto imobiliário nem tão pouco uma região. O Ecoville é uma área, um prolongamento do eixo estrutural, localizado a Oeste da cidade de Curitiba (PR). O Ecoville tem a maior oferta de imóveis à venda e de terrenos para a construção da cidade de Curitiba, tem a maior renda familiar e um dos metros quadrados mais caros da cidade (ADEMI-PR, 2011), variando entre $R \$ 6.000,00$ e $R \$ 7.000 .00$, podendo chegar a $R \$ 13.000,00$ (IMÓVEL, 2012).

O desenvolvimento imobiliário do Ecoville criou uma área de distinção, voltada para as camadas de alta renda. "Os edifícios consistem em verdadeiros condomínios fechados verticais, contando com sofisticadas áreas de lazer, tecnologia informatizada e segurança reforçada." (POLUCHA, 2010, p. 128). Suas torres isoladas de apartamentos com até 30 pavimentos e 98 metros de altura são uma tendência à estandardização desse modelo de verticalização.

\section{REFERÊNCIAS}

ADEMI-PR. Associação dos Dirigentes de Empresas do Mercado Imobiliário no Estado do Paraná. Perfil Imobiliário de Curitiba. Curitiba, Outubro, 2010.

Associação dos Dirigentes de Empresas do Mercado Imobiliário no Estado do Paraná. Região Ecoville Champagnat. In: ADEMI-PR. Associação dos Dirigentes de Empresas do Mercado Imobiliário no Estado do Paraná. Perfil Imobiliário de Curitiba. Curitiba, Outubro, 2011. p. 63-73.

FENIANOS, E. E. Bigorrilho: seu apelido é Champagnat. Curitiba: UniverCidade, 1997. (Coleção Bairros de Curitiba, v.11)

FIRKOWSKI, O. L. C. de F. Considerações sobre o grau de integração da Região Metropolitana de Curitiba na economia internacional e seus efeitos nas transformações socioespaciais. In: MOURA, Rosa; FIRKOWSKI, O. L. C. de F. Dinâmicas intrametropolitanas e produção do espaço na Região Metropolitana de Curitiba. Rio de Janeiro: Observatório das Metrópoles/Observatório de Políticas Públicas Paraná; Curitiba: Capital Editora, 2009. p. 31-60.

Olga L. C. de F. Internacionalização e produção de novos espaços urbanos em Curitiba (Brasil). In: The First International Conference of Young Urban Researchers (FICYUrb), 2007, Lisboa, 2007. p. 1-21.

13 Dentro da dinâmica imobiliária os incorporadores não atuam sozinhos, contam sempre com a anuência de outros agentes produtores do espaço urbano, como por exemplo, o Estado. Em alguns casos formam as chamadas alianças ou coalizões de interesses. Essas alianças geralmente são acordos entre incorporadores imobiliários e o poder público (SILVA, 2007). 
MILLÉO, A. IMÓVEL de luxo valorizou 225\% em 4 anos. Jornal Gazeta do Povo, Curitiba, 17 out. 2012. Caderno de Imóveis. Disponível em: <http://www.gazetadopovo.com.br/imobiliario/conteudo. phtml?tl=1\&id=1308406\&tit=Imovel-de-luxo-valorizou-225-em-4-anos>. Acesso em: 20 out. 2012.

INSTITUTO DE PESQUISA E PLANEJAMENTO URBANO DE CURITIBA. Curitiba: uma experiência em planejamento urbano: Cidade Industrial. Curitiba: IPPUC, 1975.

. Conectora 5. Área abrangente sul da Conectora (CC). Volume 4. Curitiba: IPPUC, 1980. p. 10.

. A regional desejada: etapa de planejamento de Santa Felicidade. Curitiba, março 2007. p. 1-42.

. Curitiba em dados. Pessoas residentes, segundo domicílios e os bairros da Administração Regional Santa Felicidade de Curitiba, 2010. Disponível em: <http://ippucweb.ippuc.org.br/Bancodedados/ Curitibaemdados/Curitiba_em_dados_Pesquisa.htm>. Acesso em: 20 jul. 2012.

MOURA, R.; FIRKOWSKI, O. L. C. de F. “Metrópoles e regiões metropolitanas: o que isso tem em comum?” In: IX ENCONTRO NACIONAL DA ANPUR, 2001, Rio de Janeiro. Anais de resumo. Rio de Janeiro: ANPUR, 2001. v. 1, p. 105-114.

PILOTTO, Â. Área Metropolitana de Curitiba: um estudo a partir do espaço intraurbano. 2010. Dissertação (Mestrado em Arquitetura e Urbanismo) - Programa de Pós-Graduação em Arquitetura e Urbanismo, USP, São Paulo, 2010.

POLUCHA, R. S. Ecoville: construindo uma cidade para poucos. 2010. Dissertação (Mestrado em Arquitetura e Urbanismo) - Programa de Pós-Graduação em Arquitetura e Urbanismo, USP, São Paulo, 2010.

SÁNCHEZ, F. A reinvenção das cidades para um mercado mundial. Chapecó: Argos, 2003.

SILVA, A. L. da. Loteamentos Residenciais exclusivos de Londrina: Outras fronteiras imaginárias e invisíveis. 2007. Dissertação (Mestrado em Geografia Meio Ambiente e Desenvolvimento) - Programa de Pós-Graduação em Geografia, UEL, Londrina, 2007.

THÁ INCORPORADORA. Conheça o grupo Thá. Disponível em: www.tha.com.br. Acesso em: 13 abr. 2011.

VILLAÇA, F. Espaço intraurbano no Brasil. São Paulo, Studio Nobel/Fapesp, 2001.

Recebido em 22/10/2012

Aceito para publicação em 22/10/2013 